\title{
Electronic Complaint Management System for Municipal Corporation
}

\author{
B. Sudhir \\ HOD \\ Dept. Computer Applications \\ MITS College, Madanapalle \\ AP., S. India
}

\author{
B. Regina \\ Asst. Professor \\ Dept. Computer Applications \\ MITS College, Madanapalle \\ AP., S.India
}

\author{
Sajidabhanu \\ MCA VI semester \\ Dept. Computer Applications \\ MITS College, Madanapalle \\ AP., S.India
}

\begin{abstract}
This project mainly focuses on sanitation and development of a municipal corporation. To make it possible, the people who belong to the municipal corporation are provided with an opportunity of raising a complaint regarding any issue that take place in their locality.

The issues are garbage management, water supply, electricity management, road repairs or layering of roads and threatening of animals. To raise the complaints through Electronic Complaint Management System (ECMS) for Municipal Corporation regarding the above categories, a simplified solution is designed where the different type of complaints made by people are integrated.
\end{abstract}

\section{General Terms}

Database, Security, Ranking

\section{Keywords}

Complaint Management System, Portal Management

\section{INTRODUCTION}

In a developing country like India, there is no direct communication between people government. Lack of communication between people and government create a way for bribery. Still if unethical ways are followed there is no grantee that the desired work can be finished or not within given time. It is very costly thing to sacrifice a leave to lodge a complaint in person to the municipal corporation.

\section{PURPOSE OF THE PROJECT}

The main purpose of the project is to help the public who are facing different problems in the localities by this online application. This project is having that potential to reduce the gap between people and Govt. It can control unethical work of bribe and even it can reduce the processing time.

In this project identification and solution for the complaints given by the people, rectifying them within the system generated time limit is the main concept of the project. A clear report is generated by the system which shows assignee name, complaint type/ department, etc. All the above attributes help while viewing the report of complaints. The admin examines weather the problem is rectified or not within the grace period. If it is not solved, then the report is automatically forwarded to the higher authorities so that it maintains an effective problem solving solution. The main objective of this project is to make easy the process of complaint reporting with very simplified and effective way.

This project involves major problem solving modules where these acts as best solution for incoming bulk complaints. For every submission of complaint, the user gets complaint acknowledgement. All these type of acknowledgement is generated by the computer; the solution of time may differ from the type of the complaint and category. To make any complaint, it is made mandatory for the user to mention his contact details, so that it does not receive any anonymous complaint details.

\section{LITERATURE REVIEW}

\subsection{Previous Work}

In earlier existing systems, one must visit the office and complaints given through written statement. Based on the priority, the complaint can be submitted in drop box or directly to the commissioner or the concerned department, which may take physical effort and time consuming task.

In this existing system, one cannot get any acknowledgement that the complaint has been received. Guarantee for problem solution is given through verbal communication. Hence, it is not meant for problem solution.

\subsection{Drawbacks of Existing System}

The main disadvantage of existing system is book keeping for all the complaints given by the customers. Hence, it is paper consuming task. There is no complaint acknowledgement given for the user, which is used for future references. People don't get time period for problem recovery.

The previous models which described about the complaint management, one of the related research was Razali et al.(2011)[2] , which developed a process of complaint management system which is platform for UiTM Pahang's customers to complaint and about the facilities and the services provided by the university.

\section{E-COMPLAINT}

There are several organizations which provide the facility of raising complaints, in which each of the organizations differ from each other in their type of complaint.

These organizations define the type of services related to the complaint provided by them for customers. So, we can say that the definition of type of complaint differ as the services provided by various organizations are different [3]. The meaning of customer complaint is nothing but the customer dissatisfaction [4] and this is also considered as the form of market feedback [1].

On the other hand, customer's complaint management is considered the key role for organization's success. The complaint management system acts as the survey for the customer's feedback about the organization. There are several organizations which consider the customer complaints as opportunities for their organization's development. 
By this method of complaint management, there is possibility for companies to understand the relation between the time taken for solving the complaints and the customer reliability and makes them to concentrate more on the complaints and solve them as soon as possible. Here, there may be effect of these organizations on the other organizations like government or may be any private system. The most important aspect which should be observed here is that the user's complaints are considered as the suggestions for improvement of its services.

\section{PROPOSED MODEL STRUCTURE}

\subsection{Overview chart}

The overview chart explains clearly about the system. The users, database, server, report status, wireless network and all the relations existing among them.

\subsection{System Analysis}

The proposed model which is developed does not only depend on the system's working process, but also it depends on the working of the flow of the process which needs to be considered. The proposed model acts as the platform for the users to address the problem regarding any issue and which should be handled carefully. The proposed model introduces a new user called privileged user, who has the right on the entire system, the process work flow of the privileged user is shown in the representation given below.

The privileged user has access with both admin level and customer side. He can be able to view the tasks, requests, complaints, login details of both the user and admin. The privileged user has to login into the system first, and then access the data as he wants. Privileged user can be able to view the complaints reported by the user and also the managed complaints by admin. In the managed complaints, he will check for the solved and unsolved complaints. If there are any unsolved complaints, he will take actions towards the problem.

\subsection{System Design}

This complaint handling system is mainly developed to provide the user the process of making complaint easy, it also made the process of registering a complaint through online. The different types of complaints made by different users are made integrated in a web portal.

The admin of the portal manages all the complaints and passes those complaints to the respective complaint handling departments. If the complaint is not solved within the time provided by the system, the complaint will be automatically sent to the municipal commissioner who is the head for all departments. By this process, the users are made satisfied regarding their problems.

This project makes extension to the already existed process by integrating all type of complaints together and provides solutions for those problems within the convenient time and without any effort.

\subsection{3 - Tier Concept}

The three tiers describe the separation of functionality into layers with each segment being a tier that can be located on a physically separate computer. It can be used in web applications and distributed applications. The strength in particular is when using this architecture over distributed systems. The proposed model is categorized into 3-tiers that consist of the following:

Database tier: The database tier contains data about different user's information and their details, Citizens information, list of problems pertaining to the municipality and shared people profiles.

Business tier: It consists of the admin information of the system. i.e. complaint handling and acknowledgement components.

Presentation tier: It consists of web-based user interface.

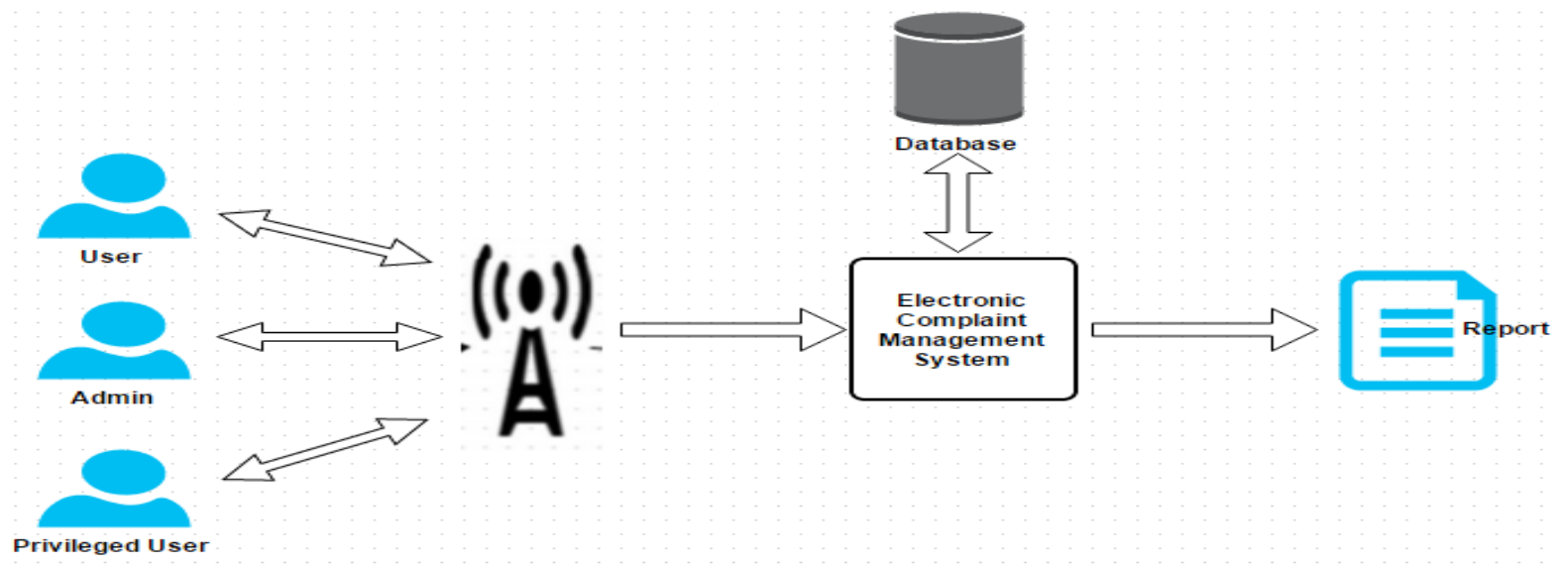

Figure 1: Overview of the System

\subsection{Implementation Design}

After the workflow process and the proposed systems have been described, the implementation model takes place which is given as follows.

\subsection{Component Diagram}

Compared with the other diagrams, component diagrams are different in their nature. These diagrams are mainly used to model the physical aspects like executables, files, documents, etc of any system. The component diagram of this system visualizes the components of the system and also explains the relationship between the components.

As the complaints, citizens and officers vary in their responsibilities, then basing on their roles, the system mainly deals with three types of roles which are user, admin and the privileged user. 


\subsubsection{User}

The user makes complaints against the provided services.

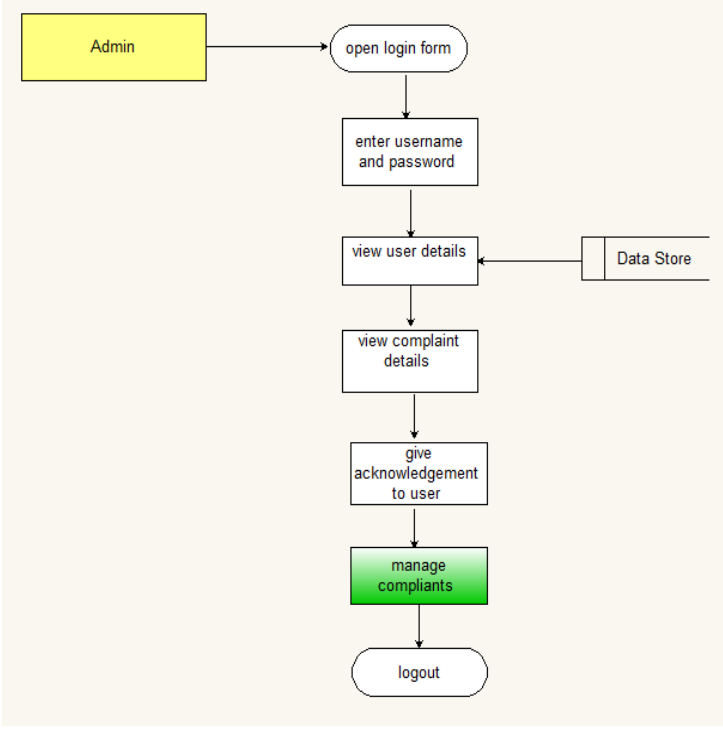

Figure 2: User level Component diagram

\subsubsection{Admin}

The admin creates system users and manage their privileges.

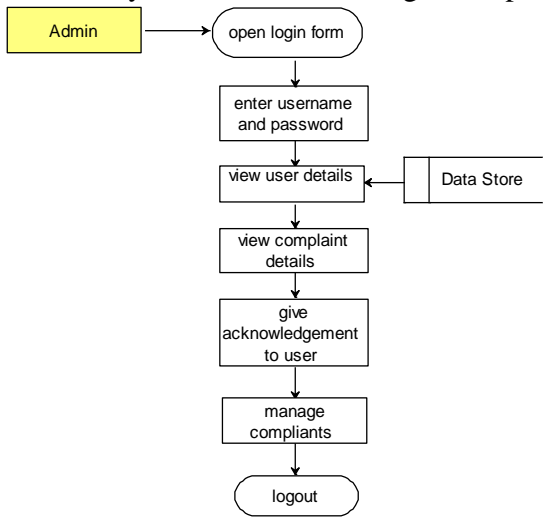

Figure 3: Admin Component Level Diagram

\subsubsection{Privileged User}

The privileged user has privilege on both the user and the admin.

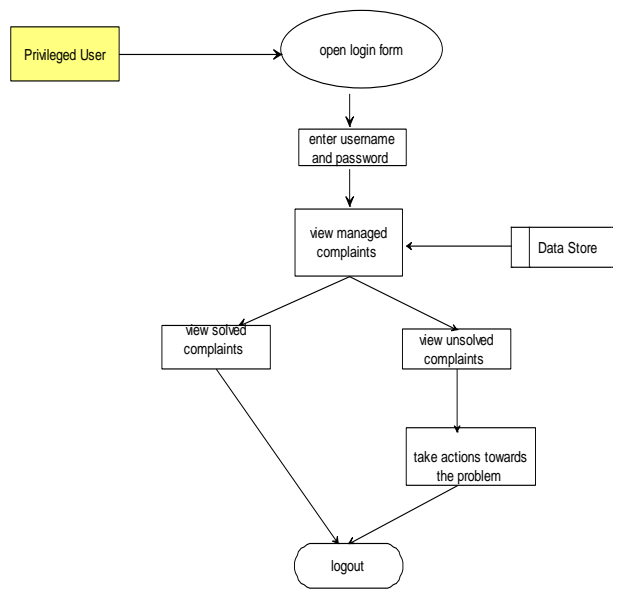

Figure 4: Privileged user Component Level Diagram
In this component diagram, the users and their functionalities are described. The user, admin and the privileged user of the system handles their functionalities and maintains the system.

\section{WORKING CONDITION}

This web based application develops in JSP and mySql is used as backend. The developed model consists of several modules like Homepage, Registration page, User login, Admin login and Privileged user login.

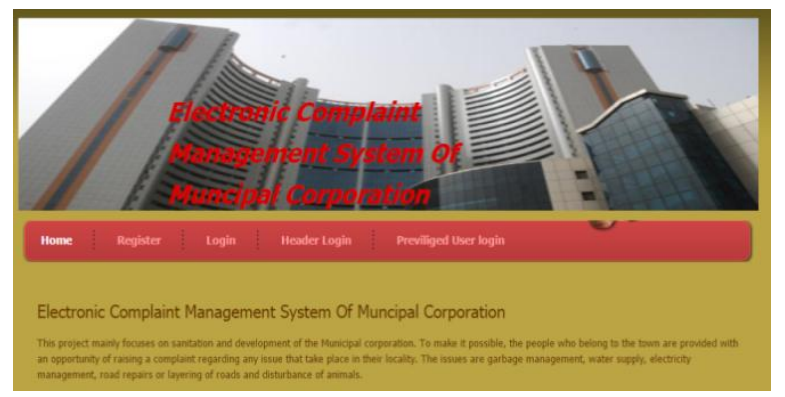

Figure 5: Home Page

A registration is provided to all the users to know whether the user is valid or not. This can be verified through several components like username, password, mobile number, Aadhar number and complaint type.

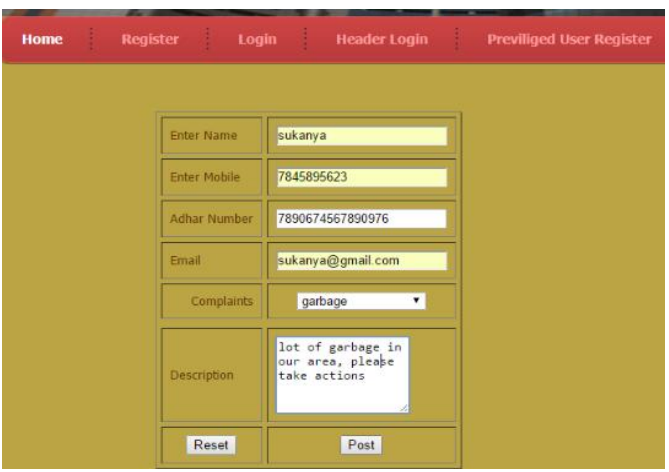

Figure 6: Login Page

Here, the user needs to enter the details with his required credentials. The main credential considered in this system is Aadhar card number, by the help of which it is possible for the admin to identify the genuine address of the user so that to validate the complaint posted by that user or not.

The main types of complaints of which the actions are taken by this system are considered as the water problems, electricity problems, garbage problems, animal problems and repairing of roads respectively. All these type complaints are hierarchied in the order of time taken by that that particular complaint to be solved as well the issues which mostly occur in the Municipal Corporation.

Once if a complaint has been raised by any user, there will be a path through which the complaint passes for that complaint to be solved. First the user or the citizen will raise the complaint into the system, from which the complaint will be directly received by the admin. The admin will check whether the complaint is valid or not and then passes that complaint to the head of that particular department and if the actions are not taken regarding that complaint in the given time, the complaint will be then passed to the privileged user who is main user having access over the entire system, and then he 
will take the required actions for that complaint to be solved. For example, if the complaint regarding the electricity problem has risen by the user, the complaint will be first passed to the admin; the admin will then forward that complaint to the head of the electricity department, i.e. the executive engineer who takes the required actions to solve that issue. After the executive engineer, the privileged user of the system i.e. the Commissioner will be able see all the solved and unsolved complaints by the executive engineer. The privileged user after taking the actions regarding any issue will send a confirmation message to the admin that the complaint has been solved so that the admin will be able to know and update the status of that complaint.

\begin{tabular}{|c|c|c|c|c|c|}
\hline Name & Mobile Number A & Adhar Number & Complaints & Description & Email \\
\hline sajjda & 9391399143 & 1238978 & firstclass & problesm in this ward, please take actions & sajida@gmail.com \\
\hline danil & 7889788945 & 45788956 & 6 secondelass & please take actions in this ward. & danil@yahoo.com \\
\hline scott & 8978897889 & 45987889 & firstclass & no water supply from past 2 days & scot@@gmail.com \\
\hline jessy & 8978458978 & 45788956 & secondelass & pleasec clean the garboge & jessy@@gmail.com \\
\hline abhil & 7889788945 & 45987889 & thirdelass & $\begin{array}{l}\text { there is a problem with animals, please take } \\
\text { actions. }\end{array}$ & aahil|@gmail.com \\
\hline
\end{tabular}

Figure 7: List of complaints Raised by Citizens

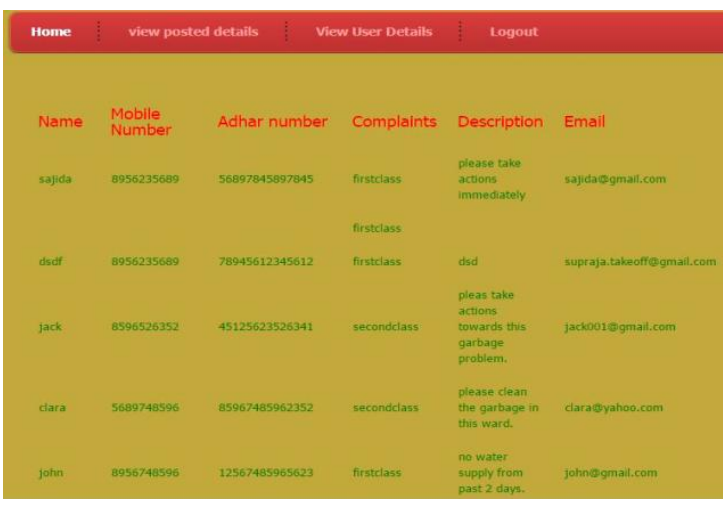

Figure 8: List of Complaint in Priority Manner

There will be a priority given for every complaint to be solved. Depending upon the problem, the people belonging to the respective department will take actions. The priorities for the complaints to be solved is given with the particular time period like, for electricity problem after the complaint has given it will be solved within the few hours of the day, to take actions regarding the water problems and the garbage problems will take a complete day or two. To take actions regarding the repairing of roads and the security with animals will take about a week. These are the approximate time periods taken according to the time taken to solve complaints by the authorities of Municipal Corporation.

A clear report is generated by admin where all the managed complaints are mentioned like the complaint category, complaint status, complaint category, from which user the complaint has been raised. A database is maintained where all the data is maintained the user details and the complaint details which is downloaded as the report generated which is shown in the below picture.

\section{CONCLUSIONS}

In this model, it is explained about the working procedure of the system, the roles involved in the system and the activities and responsibilities those users. This paper presents the overview of the analysis and development of the complaint management system of Municipal Corporation.

There will be a remarkable result will be obtained by the implementation of this project and also they help in encouraging the development of this type of complaint management systems or more complex systems. Generally the complaints and other types of feedback play an important role in the development of any organization and to interact with the customers in a better way. This system can be taken as initiation for the systems which will be developed onfuture and which are related to complaint management systems.

\section{REFERENCES}

[1] Fornell C., \& Westbrook A. Robert, "The Vicious Circle of Consumer Complaints", journal of Marketing, (summer)(1984), 68-78.

[2] Razali R., Abd Halim K.N., \& Jusoff K., "Quality Improvement of services in Unversiti Teknology Mara Pahang from a Management Perspective." Management Science \& Engineering Vol.5, No.1, (2011), pp.71-80.

[3] Najar, A.S., Al-Sukhni, H.A., \& Aghakhani, N., "The Application of Service-oriented Architecture in Ecomplaint System." Paper presented at (ICCSN '10) the Second International Conference on Communication software and Networks, (2010, 26-28 Feb.@2010).

[4] Yi, Yooujae, "A Critical Review of Customer Satisfaction". In Review of Markiting, Valerie A, Zeithaml, ed. Chicago, American Marketing Association, (1990).

[5] ESRAA ABD EL-AZIZ ABD EL-SADEK AFIFY, "A model for Customer Complaint Management system using SOA", Management Information System Department, Modern Academy for Computer Science \& Management Technology, CAIRO, EGYPT.

[6] http://www.ibimapublishing.com/journals/JMRCS/ 2012/624789/624789.pdf

[7] http://www.indiaurbanportal.in/b1 estpractices/best practices $81 /$ bestpractices810.pdf

[8] http://www.freeproject.co.in/source/ComplaintManagement - System.aspx ?pf=Java\&t=web

[9] http://grietinfo.in/projects/main/mca2012/cd-1-3doc.pdf

[10] http://www.techzoo.org/projects/online-complainmanagement-system-php-project.html 